\title{
THE LENGTH OF STEM-FINAL VOWELS IN COLLOQUIAL ARABIC*
}

\author{
John J. McCarthy \\ University of Massachusetts, Amherst
}

\section{Introduction}

In Cairene Arabic, word-final vowels are short, but the same vowels are long when followed by a suffix, as shown in (1).

(1) Cairene Arabic $\breve{v} \sim$ v: alternation (Watson 2002:202)

\begin{tabular}{|c|c|c|}
\hline Pábu "father" & Pabú sja $^{\prime}$ & "my father" \\
\hline & Rabúk & "your father" \\
\hline ver" & yat á sha & "her cover" \\
\hline you (f. s.) were" & ma kuntíus & "you (f. s.) were not" \\
\hline 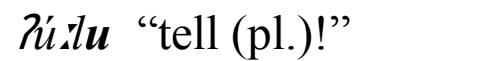 & Rulú & "tell (pl.) me!" \\
\hline
\end{tabular}

All stem-final vowels alternate in this way. There are no stem-final vowels that remain short before a suffix $(* t a b u / t a b u k)$, nor are there any stem-final vowels that are long word-finally (*katu $:$ katu $: k)$.

These facts are not limited to Cairene. Nearly all varieties of colloquial Arabic have similar alternations. Because this phenomenon is so pervasive, many analysts have discussed it, and there are two schools of thought about how it should be accounted for. In the view of some, all stem-final vowels are short in underlying representation (e.g., / $/ \mathrm{abu} /$ ), and there is a process lengthening them before a suffix. Proponents of

* For their comments on an earlier version of this paper, I am grateful to Ellen Broselow, Maria Gouskova, Bruce Hayes, Shigeto Kawahara, and Jaye Padgett. 
this view include Abdel-Massih et al. (1979:323), Broselow (1976:106118), and Watson (2002: 201-203) on Cairene, Bohas (1978: 98) on Damascene, Abdul-Karim (1980), Brame (1971: 584), and Haddad (1984) on Lebanese and Palestinian, and Hamid (1984) on Sudanese. Another group of analysts favors stem-final vowels that are underlying long (e.g., / Rabu:/), with shortening word-finally. This approach is espoused by Abdo (1969) and Abu-Salim (1982) on Lebanese and Palestinian, Abu-Mansour (1987:134) on Mekkan, and Glover (1988) on Omani. Actual phonological differences among these dialects are not sufficient to explain this divergence of opinion. In fact, Angoujard (1978: 16), discussing Tunisian Arabic, tosses up his hands, saying, 'à choisir entre une règle d'abrégement et une règle d'allongement ... à vrai dire, je n'en ai pas trouvé de clairement décisifs.'

It might seem, then, that the underlying length of stem-final vowels in colloquial Arabic is indeterminate. In this chapter, I will argue that Optimality Theory (Prince and Smolensky 1993) resolves this indeterminacy. Two aspects of OT are important to the argument. One is richness of the base (ROTB), the thesis that there are no languageparticular restrictions on underlying representations. The other is the hypothesis that there is a universal constraint-set called CON. ROTB and the universality of CON together force a resolution of this indeterminacy, supplying both the linguist and more importantly the language learner with a fully determinate answer to the question of the underlying representation. Under ROTB, an OT grammar of Cairene Arabic must correctly dispose of inputs with stem-final short and long vowels, both of which are served up by the rich base. An underlying stem is correctly disposed of it is mapped onto a pattern of (non)alternation that is actually observed in the language. When this process of reasoning is followed through, we are led to the conclusion that the underlying form of "father" is /Rabu:/, with a long vowel.

\section{Theoretical Background}

I assume familiarity with the main premises of Optimality Theory at the level of introductory works like Kager (1999), McCarthy (2002), or Tesar, Grimshaw, and Prince (1999). For present purposes, the most important thing about OT is its dichotomy between the languageparticular and the universal. The set of linguistic constraints, called CON, 
is universal in the sense that all constraints are present in the grammars of all languages. Languages differ, however, in the ranking imposed on CON: two languages (or two dialects) will have different rankings of CON. The strongest hypothesis is that, apart from vocabulary, ranking is the only difference between languages.

One consequence of this hypothesis is that all systematic, language-particular restrictions on underlying forms are eliminated. Standardly, generative phonology has relied on devices like morphemestructure constraints, lexical redundancy rules, or underspecification as part of the analysis of many generalizations. All of these devices are now gone; in its purest form, OT says that linguistic generalizations must be entirely accounted for in the grammar without any assistance from special constraints on the lexicon.

The assumption that the lexicon is unrestricted is called 'Richness of the Base' (ROTB). For example, ROTB entails that English cannot have a morpheme structure constraint against initial stop+nasal clusters, which might appear necessary to explain the impossibility of words like *bnick. Rather, the ill-formedness of *bnick is the responsibility of the grammar, which says that $b n$ is an impossible syllable-initial cluster. This does not mean that the word nick is derived, absurdly and perversely, from underlying /bnIk/; rather, it means that, if the grammar is presented with the input/bnIk/, the output is not *bnick but something else. In other words, knowledge of phonotactics is encoded in the grammar's intolerance for phonotactically impermissible sequences and not by preemptively removing them from the lexicon.

ROTB imposes an obligation on the analyst to make sure that the grammar gives phonotactically permitted results even when presented with unpronounceable inputs. Care must be taken to ensure that the grammar is not being helped along by convenient, implicit restrictions on inputs. The 'base' — that is, the set of inputs to which the grammar is applied - must be 'rich' in the sense that it represents all of the diverse possibilities afforded by the world's languages.

OT is an inherently typological theory. Because it includes an explicit statement of what is universal and what is language particular, it makes strong claims about typology, the ways in which languages can and cannot differ. Typology is the acid test of any proposed constraint. Since CON is universal, any hypothesized addition to CON — that is, any 
newly-conceived constraint - needs to be checked out under various language-particular rankings. A specific theory of CON is therefore a theory of what are possible and impossible human languages.

\section{Analysis}

In standard generative phonology, which does not assume ROTB, the problem in Cairene can be stated like this: given a restricted set of underlying forms, how does the grammar yield the Pabu Pabuik alternation? In OT, which assumes ROTB, the problem is very different: given any input, how does the grammar derive the Pabu Rabu:k alternation while systematically excluding other logically possible but factually non-occurring patterns of alternation, particularly tabu tabuk (short throughout) and katurkatu:k (long throughout)? This shift in perspective focuses attention on what does not occur as well as what does. In the standard theory, the explanation for what does not occur is distributed between the lexicon and the grammar; in OT, the explanation is entirely the responsibility of the grammar.

In keeping with ROTB, the set of underlying representations that must be considered should be diverse in all relevant respects. Therefore, we need to consider underlying stems that end in consonants, like hypothetical /batak/, stems that end in short vowels, like hypothetical /takabu/, and stems that end in long vowels, like hypothetical/kabata:/. From observation, we know that only two surface patterns actually occur, nonalternating consonant-final stems like daras darasha "he learned/he learned it (f.)" and alternating vowel-final stems like nisi nisi.ha "he forgot/he forgot her". The problem, then, is to explain why the grammar only allows two different patterns - surface C-final and alternating $\mathrm{V}$-final - when the rich base supplies material for three different patterns - underlying C-final, short V-final, and long V-final.

A three-way underlying contrast is mapped onto a two-way surface contrast. Which underlying distinction is being neutralized? There are six logically possible ways of mapping three input items onto two output items. (For each input item, there are two choices of an output item to map it to, giving $2^{3}$ minus 2 for the cases where all inputs have mapped to a single output). We will examine them systematically, excluding all but the correct one. 
In three of the six logically possible systems, something strange happens: an underlying consonant-final stem maps onto a surface vowelfinal pattern, while an underlying vowel-final stem maps onto a surface consonant-final pattern, as shown in (2).
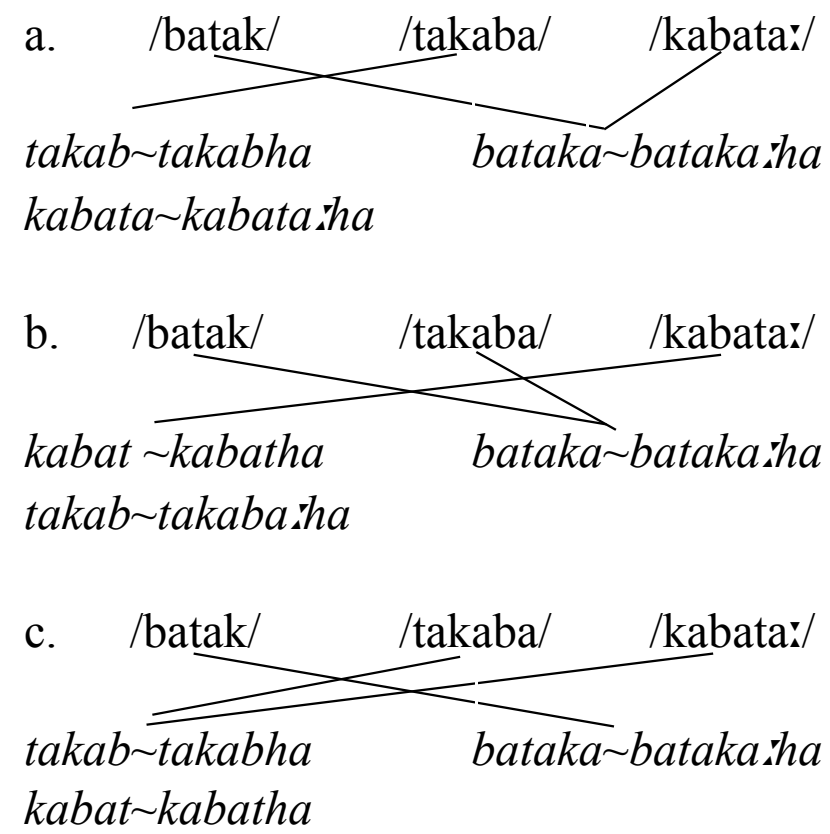

In (2a), for example, underlying /batak/ gains a short vowel when unsuffixed and a long vowel when suffixed. Meanwhile, underlying /takaba/ loses its final vowel in both the unsuffixed and suffixed forms. Similar gyrations appear in the other two systems.

Though these possibilities are supplied by considerations of logic, they are not likely to be possible human languages. What makes these patterns strange is that all of them involve circular chain shifts - that is, mappings where $/ \mathrm{A} / \rightarrow B$ and $/ \mathrm{B} / \rightarrow A$. In (2a), the circular shift is $/ \mathrm{CV \# /}$ $\rightarrow C \#($ i.e., $/$ takaba/ $\rightarrow$ takab $)$ and $/ \mathrm{C \# /} \rightarrow C V \#(/$ batak $/ \rightarrow$ bataka $)$. In $(2 \mathrm{~b})$, the circular shift is /CV + Suffix/ $\rightarrow C+$ Suffix and /C+Suffix/ $\rightarrow$ $C V:$ Suffix. Example (2c) combines both of these circular chain shifts.

Moreton (2003) proves that 'classic' OT grammars are incapable of producing circular chain shifts. The core of his proof is the observation that a classic OT grammar is just exactly a ranking of markedness and faithfulness constraints, so the only possible reason to be unfaithful is to become less marked. The mappings /A/ $\rightarrow B$ and $/ \mathrm{B} / \rightarrow$ 
$A$ are both unfaithful, so both must improve markedness. But that's not possible, since no single constraint ranking can provide that $B$ is less marked than $A$ and $A$ is also less marked than $B$. Circular chain shifts are not only incompatible with OT; Moreton offers sound empirical arguments that they are impossible in human language. Since the systems in (2) all involve circular chain shifts, they can be ruled out on both theoretical and empirical grounds.

This leaves the noncircular systems in (3) for further contemplation.
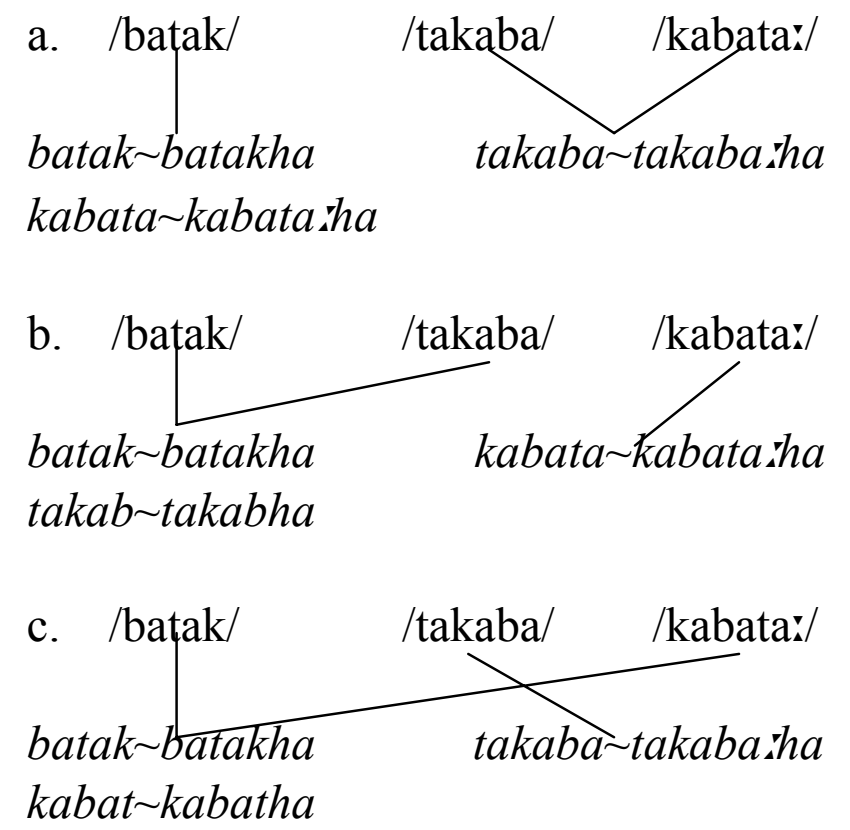

By first excluding the other two systems, I will show that (3b) is correct.

System (3c) requires a process that deletes stem-final long vowels - but not short vowels - when they are word-final or presuffixal. Arguably, such a process is impossible if the constraint-set CON is universal. Since the universal constraints are not known to us in advance, but must be hypothesized based on empirical investigation, this argument is necessarily somewhat indirect. The essence of the argument is that (3c) would require CON to include a constraint with implausible typological consequences. In other words, $(3 \mathrm{c})$ cannot be correct because it indirectly predicts unattested phenomena in other languages.

A constraint hierarchy capable of yielding (3c) must be able to produce the mappings in (4). 
(4) Mappings for (3c)

Word-final Presuffixal

$/ \mathrm{V} / \rightarrow V$ (identity) $\quad / \mathrm{V} / \rightarrow V^{\prime}$ (lengthening)

$/ \mathrm{V}: / \rightarrow \varnothing($ deletion $) \quad / \mathrm{V}: / \rightarrow \varnothing($ deletion)

That is, (3c) requires that short vowels be lengthened in the same presuffixal context where long vowels are deleted. This is a type of noncircular chain shift: $/ \mathrm{CV}+$ Suffix $/ \rightarrow C V \boldsymbol{r}+$ Suffix and $/ \mathrm{CV} \mathbf{2}+$ Suffix $/ \rightarrow$ $C+$ Suffix. In addition, (3c) has $/ C V: \# / \rightarrow C \#$.

In general, an OT grammar is capable of producing a chain shift like this one, where $/ \alpha / \rightarrow \beta$ and $/ \beta / \rightarrow \varnothing$ in the same context. (On the general theory of chain shifts in OT, see Kirchner 1996, Lubowicz 2003, Moreton and Smolensky 2002, Prince 1996). The existence of the $/ \beta / \rightarrow$ $\varnothing$ mapping shows that some markedness constraint $* \beta$ dominates the anti-deletion faithfulness constraint MAX. To get the mapping $/ \alpha / \rightarrow \beta$, then, it is necessary to block the effect of the ranking * $\beta$ over MAX when the input is $/ \alpha /$. This requires that CON include a faithfulness constraint $\mathrm{F}_{\mathrm{CS}}$ that militates against the fell-swoop $/ \alpha / \rightarrow \emptyset$ mapping but not the $/ \alpha / \rightarrow \beta$ and $/ \beta / \rightarrow \varnothing$ mappings. Ranked above $* \beta, \mathrm{F}_{\mathrm{CS}}$ prevents $/ \alpha /$ from going all the way to $\varnothing$, thereby allowing the $/ \alpha / \rightarrow \beta$ mapping to win.

Concretely, to analyze the $/ \mathrm{CV}+$ Suffix $/ \rightarrow C V:+$ Suffix and $/ C V:+$ Suffix/ $\rightarrow C+$ Suffix chain shift in (3c),we must posit a faithfulness constraint $\mathrm{F}_{\mathrm{CS}}$ that forbids the fell-swoop deletion mapping /CV+Suffix/ $\rightarrow{ }^{*} C+$ Suffix, while still allowing the deletion mapping /CV + Suffix $/ \rightarrow$ $C+$ Suffix. Since short vowels do not delete but long vowels do, $\mathrm{F}_{\mathrm{CS}}$ must be a faithfulness constraint that is violated when a short vowel deletes but not when a long vowel deletes. Therefore, (3c) can be analyzed only if CON includes a faithfulness constraint $\operatorname{MAX}(\breve{v})$ that protects short but not long vowels from deletion.

Independent typological considerations show that CoN must not include such a constraint, from which it follows that (3c) cannot be the correct analysis. Beckman (1998) argues that there are special positional faithfulness constraints protective of long vowels - just the opposite of $\operatorname{MAX}(\breve{v})$. A typological argument for long-vowel faithfulness is that long vowels are often preserved in the same environments where short vowels delete or otherwise neutralize. In fact, the medial syncope processes of 
Cairene and other Arabic dialects show precisely this pattern of preservation of underlying long vowels in situations where short vowels are deleted, as we will see later. If CON were to supply a constraint $\operatorname{MAX}(\breve{v})$, we would expect to find languages where well-understood, uncontroversial syncope processes affect only long vowels and not short ones. No such language has been observed, so it is imperative for typological reasons that CON not contain $\operatorname{MAX}(\breve{v})$. But without $\operatorname{MAX}(\breve{v})$, there is no way to analyze the system of mappings in (3c). We can therefore eliminate it as a possible account of Cairene Arabic.

This leaves the choice to (3a) vs. (3b). In (3a), the unfaithful mappings include both word-final shortening and presuffixal lengthening, as in (5).

$$
\begin{array}{ll}
\text { Mappings for (3a) } & \\
\text { Word-final } & \text { Presuffixal } \\
/ \mathrm{V} / \rightarrow V \text { (identity) } & / \mathrm{V} / \rightarrow V: \text { (lengthening) } \\
/ \mathrm{V}: / \rightarrow V \text { (shortening) } & / \mathrm{V} / \rightarrow V: \text { (identity) }
\end{array}
$$

In (3b), the unfaithful mappings include deletion and shortening, as shown in (6).

(6) Mappings for (3b)

$$
\begin{array}{ll}
\text { Word-final } & \text { Presuffixal } \\
/ \mathrm{V} / \rightarrow \varnothing(\text { deletion) } & / \mathrm{V} / \rightarrow \varnothing \text { (deletion) } \\
/ \mathrm{V} / \rightarrow V \text { (shortening) } & / \mathrm{V}: / \rightarrow V^{\prime} \text { (identity) }
\end{array}
$$

As we will see, $(3 b) /(6)$ is the right solution.

I will begin comparing these two systems by analyzing that which they share: shortening of word-final long vowels. This phenomenon has ample typological precedents. For example, in Axininca Campa, an Arawakan language of Peru, word-final vowels are shortened except in monosyllables, where they are required for reasons of foot binarity. The data are given in (7). 
(7) Final shortening in Axininca Campa

(McCarthy and Prince 1993, Payne 1981, Spring 1990)

Noun "my"+Noun

\begin{tabular}{|c|c|c|c|}
\hline /sampa:/ & sampa & nosampa:ti & "balsa" \\
\hline /sawo:/ & sawo & nosawo sti & "case" \\
\hline $\begin{array}{l}/ \mathrm{ts}^{\mathrm{h}} \mathrm{imi} / \mathrm{I} \\
\text { Compare }\end{array}$ & $t^{h} i m i$ & nots imisti & "ant" \\
\hline$/ \mathrm{mi} /$ & $m i r$ & nomisni & "otter" \\
\hline ma & sima & nosimani & "fish" \\
\hline /tyokori/ & tokori & notfokoriti & "armadillo" \\
\hline
\end{tabular}

Axininca has a left-to-right iambic stress system, but words like sáwo are stressed trochaically.

Final shortening in Axininca is primarily a consequence of two markedness constraints. One, NonFinALITY (Prince and Smolensky 1993), prohibits word-final stressed syllables. The other, WSP (for 'weight to stress principle', from Prince 1990), is violated by unstressed heavy syllables. NONFINALITY rules out *(sawó:) (the parentheses delimit metrical feet) and WSP rules out faithful but trochaic *(sáwo:). WSP and NONFINALITY dominate an appropriate faithfulness constraint, such as MAX- $\mu$, which prohibits shortening. This constraint is defined in (8).

MAX- $\mu$

Every input mora has an output correspondent.

For an account of Axininca shortening within an analysis of the full stress system, see the appendix to McCarthy and Prince (1993).

The Axininca analysis can be easily adapted for Cairene Arabic. The well-known Cairene stress system assigns moraic trochees from left to right (Hayes 1995: 67-71, McCarthy 1979). NONFINALITY ensures that the last syllable is unstressed, even if it is underlying / $\mathrm{CV}: /$ and could in principle support a bimoraic foot. The ranking argument appears in tableau (9). 


NONFINALITY, WSP $>>$ MAX- $\mu$
\begin{tabular}{|l||c|c|c|}
\hline /kabata:/ & NonFINALITY & WSP & MAX- $\mu$ \\
\hline \hline a. $\quad$ (kába)ta & & & $*$ \\
\hline b. (kàba)(tái) & $* !$ & & \\
\hline c. $\quad$ (kába)ta: & & $* !$ & \\
\hline
\end{tabular}

This tableau supplies two ranking arguments. Because final stress is prohibited at the expense of shortening, NonFInALITY must dominate MAX- $\mu$. And because long vowels must bear stress or else shorten, WSP also dominates MAX- $\mu$.

The existence of certain exceptional forms tends to confirm this analysis. Cairene has some words that have stressed final long vowels. Most involve a third masculine singular object or possessor, like katabú: "he wrote it", but there are also a few words like gató $:$ "cake". Significantly, these forms are doubly exceptional: they have final stress and final length. This is the expected correlation according to (9): if a final long vowel is exceptionally stressed, then it will not shorten because WSP is not in danger of being violated.

It is possible to go a step further and note that Cairene not only requires long vowels to bear stress, it actually requires them to bear main stress. (Other Arabic dialects are not usually so restrictive; they allow long vowels to occur in secondary-stressed syllables as well.) When suffixation draws main stress away from an underlying long vowel, it obligatorily shortens (Abdel-Massih et al. 1979: 326, Broselow 1976: 16-19, Mitchell 1956: 111-112, Watson 2002: 226-228). Examples are given in (10).

(10) Shortening without main stress

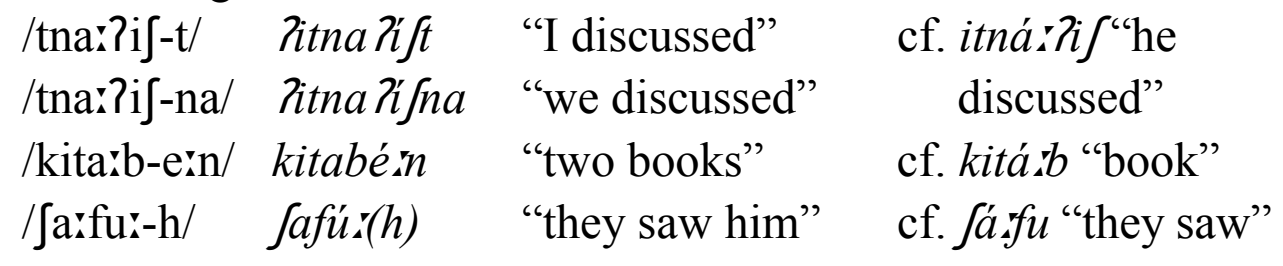


Since there is considerable dispute as to whether Cairene has audible secondary stress and, if so, where it is located (de Lacy 1998, Harms 1981, Kenstowicz and Abdul-Karim 1980, Welden 1977, 1980), it is safest to formulate the observation in terms of feet: in Cairene, it is not sufficient for long vowels to be in foot-head position. They must be in the head of the head foot itself, bearing the main stress of the word. A constraint stronger than WSP, call it WMSP (for 'main stress'), should therefore replace WSP in tableau (9). The point is that shortening of nonmain-stressed vowels, which is required to account for loss of vowel length word-finally, is also observed word-medially.

So much for the shared phonology of the two mapping systems $(3 a) /(5)$ and $(3 b) /(6)$. This brings us now to the points of divergence between then. In (3a)/(5), underlying short vowels lengthen before a suffix. In $(3 b) /(6)$, underlying short vowels delete finally and before a suffix, but underlying long vowels do not. Neither presuffixal lengthening nor presuffixal deletion seem particularly attractive on typological grounds. Can either of them be rationalized within a restrictive, typologically secure theory of CON?

Rationalizing (3a)/(5) seems quite hopeless. The lengthening process in $(3 \mathrm{a}) /(5)$ requires a markedness constraint that favors long vowels before suffixes, but language typology offers little support for such a constraint. Surface contexts that are known to favor vowel length cross-linguistically are word-final position, in open syllables, under stress, and before certain segments, such as voiced obstruents. There may be other lengthening contexts, but presuffixal position does not seem to be one of them. ${ }^{1}$

1. Bruce Hayes points out that Siptár and Törkenczy (2000: 56-58, 170-173) describe a lengthening process in Hungarian that affects low vowels before suffixes: alma 'apple', almát 'apple (adj.)'; epe 'bile', epés 'bilious'. (The long low vowels are spelled $a$ and $e ́$ in Hungarian.) The argument that this is presuffixal lengthening rather than word-final shortening is based on words with nonalternating final long vowels, such as burzsoá 'bourgeois', burzsoát 'bourgeois (acc.)'.

There are good reasons to be skeptical of this analysis. Siptár and Törkenczy point out (p. 146) that "[w]ord-final $a$ is rare and final $e$ is relatively infrequent". Final $a$ occurs in two suffixes and some "function words, abbreviations, and interjections", numbering altogether about 15 . Only two lexical morphemes end in á, one of which is burzsoá. About 130 lexical morphemes end in é, but all are borrowings. Perhaps there is no final length contrast; rather, final $a$ is an outright exception, and final $e$ is limited to the loan-word stratum (cf. Ito and Mester 1995). 
In this light, it is striking that the majority of previous analysts nonetheless assume presuffixal lengthening (see the citations at the end of section 2). This no doubt reflects the pervasive disregard for typological considerations in standard generative phonology. Positing a traditional rule brought with it no typological commitments whatsoever, because rules were not seen as the basis of language universals, though rule notation was. This meant that the analyst (and the learner?) were free to posit even typologically unsupportable rules to suit the exigencies of language description.

Typological considerations are also helpful in understanding what is going on in $(3 b) /(6)$. Deletion of word-final short vowels - that is, apocope - is a common process cross-linguistically. Other languages with apocope processes, some of which are morphologized, include Hidatsa (Harris 1942), Kagoshima Japanese (Kaneko and Kawahara 2002), Lardil (K. Hale 1973), Latvian (Halle and Zeps 1966), Lithuanian (Lightner 1972), Middle High German (Raffelsiefen 1999), Odawa (Piggott 1975), Ponapean (Howard 1972: 179-81), and Woleaian (Sohn 1975). Because the typological situation is so favorable, this aspect of $(3 b) /(6)$ presents no problem for CON.

Among the markedness constraints believed to compel apocope is FINAL-C, which is defined in (11).

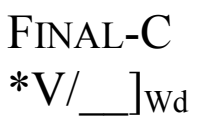

'Word-final vowels are prohibited'

$=$ 'Every phonological word ends in a consonant.'

The typological support for this constraint comes not only from several of the apocope cases mentioned above but also from diverse phenomena like these: epenthesis in Makassarese (Aronoff et al. 1987, McCarthy and Prince 1994) adds a final ? after an epenthetic vowel (/rantas/ $\rightarrow$ rantasa? "dirty"); Semitic stem templates (McCarthy and Prince 1990) are normally consonant-final; in Yapese, all words, including the output of a truncation process, are consonant-final (Jensen 1977, Piggott 1991); and intrusive $r$ in the Boston dialect creates consonant-final phonological words (McCarthy 1993). Ranked above MAX-V in Arabic, FInAL-C favors outputs with apocope over their faithful competitors, as tableau (12) shows. 
(12)

\begin{tabular}{|c|c|c|}
\hline /takaba/ & FINAL-C & MAX-V \\
\hline a. takab & & $*$ \\
\hline takaba & $*$ & \\
\hline
\end{tabular}

Observe that final shortening and final deletion are encouraged by different markedness constraints, WSP and NONFINALITY in the case of shortening (9) and FINAL-C in the case of deletion (12). Typological considerations show that this is correct, because final shortening and apocope can be decoupled. The Arabic dialect of San'a, Yemen is like Cairene in relevant respects except that word-final vowels are long (Watson 2002), showing that there can be apocope without shortening. As for shortening without apocope, Axininca Campa (7) is a convenient example. As expected, even in languages with both shortening and deletion, such as Southeastern Tepehuan, the conditions on them may be completely different (Gouskova 2003). If a single markedness constraint were responsible for both final shortening and final deletion, then it would not be possible to analyze these languages that have one but not the other or that have both though under different conditions.

Overly aggressive enforcement of FINAL-C presents a problem: it predicts apocope of final long vowels, which, according to $(3 b) /(6)$, shorten but do not delete. The solution has already been hinted at. Faithfulness constraints may be more protective of long vowels than their short counterparts. The typologically well supported positional faithfulness constraint $\operatorname{MAX}(\mathrm{V}:)$ dominates FINAL-C, blocking apocope of long vowels. Tableau (13) certifies this ranking argument.

$\operatorname{MAX}(\mathrm{V}:)>>$ FINAL-C $(>>$ MAX-V)

\begin{tabular}{|l||c|c|c|}
\hline /kabata:/ & MAX(V:) & FINAL-C & MAX-V \\
\hline \hline a. $\quad$ kabata & & $*$ & \\
\hline b. $\quad$ kabat & $* !$ & & $*$ \\
\hline
\end{tabular}


More generally, $\operatorname{MAX}(\mathrm{V}:)$ blocks all syncope processes in Cairene and other dialects (Gouskova 2003). Though short vowels delete under various conditions, long vowels never do.

As (13) shows, MAX(V:) protects long vowels from deletion even when they are shortened in the output. This is also true for Cairene's medial syncope process, which never affects underlying long vowels, even when they have been shortened because they do not bear main stress. Some reflection about constraint formulation shows why. $\operatorname{MAX}(\mathrm{V}:)$ references a vowel's input rather than output length. A definition for this constraint appears in (14). ${ }^{2}$

$\operatorname{MAX}(\mathrm{V}:)$

Let $\mathrm{V}_{\mathrm{i}}$ be a long vowel in the input. Then there exists $\mathrm{V}_{\mathrm{O}}$ in the output where $\mathrm{V}_{\mathrm{i}} \Re \mathrm{V}_{\mathrm{O}}$.

'Input long vowels have output correspondents.' = 'Long vowels cannot be deleted.'

Why couldn't MAX(V:) be formulated as a constraint prohibiting deletion of output long vowels? It's just a point of logic: if a segment is deleted, it has no output correspondent, so it is neither long nor short in the output.

The other unfaithful mapping in system $(3 b) /(6)$ is deletion of short stem-final vowels before a suffix. Regarded purely as an effect of the phonology, this seems just as dubious as presuffixal lengthening, which damned the approach in $(3 a) /(5)$. But it need not be regarded as purely an effect of the phonology.

The problem, in essence, is that $(3 \mathrm{~b}) /(6)$ requires underlying stemfinal short vowels to delete not only word-finally, where the deletion process is phonologically motivated apocope (12), but also presuffixally, where it is not phonologically motivated. Cairene Arabic has phonologically motivated syncope, but the conditions encouraging it have no intrinsic connection to presuffixal position (cf. Gouskova 2003). Rather, presuffixal deletion can be regarded as a kind of overapplication of word-final deletion. (The term 'overapplication' is used here in the

2 The constraint definition in (14) refers to the correspondence relation $\Re$, for which see McCarthy and Prince (1995, 1999). 
sense of McCarthy and Prince $(1995,1999)$ and Benua (1997), following Wilbur (1974).) Presuffixal deletion mirrors word-final deletion, carrying the effect of a phonologically-motivated process into regions of the paradigm where the phonological motivation is absent.

Phenomena like this are well-known, and they have historically been the basis for the transformational cycle (Chomsky, Halle, and Lukoff 1956), for the theory of Lexical Phonology (Kiparsky 1982, Mohanan 1986), for output-output correspondence (Benua 1997), and for stratal OT (Kiparsky 2003 and many others). Under the latter two theories and related approaches within OT, the idea is that faithfulness to the surface form takab (from/takaba/) is responsible for the triumph of takab-Sfx (from /takaba-Sfx/) over *takaba-Sfx. Both OO correspondence and stratal OT are compatible with the data; for concreteness, I will work out the OO approach in detail.

The output-output constraint OO-DEP- $\mathrm{V}^{3}$ dominates input-output MAX-V, favoring takab-Sfx over *takaba-Sfx because the latter contains a stem-final vowel that has no OO correspondent in the unsuffixed base form takab. The ranking argument appears in (15).

OO-DEP-V >> MAX-V
\begin{tabular}{|c||c|c|}
\hline takaba-SfX/ & $\begin{array}{l}\text { OO-DEP-V } \\
\text { (cf. takab) }\end{array}$ & MAX-V \\
\hline \hline a. takab-Sfx & & $*$ \\
\hline b. takaba-Sfx & $* !$ & \\
\hline
\end{tabular}

Apocope overapplies because high-ranking OO-DEP-V forbids zero/vowel alternations within morphologically related forms. In effect, it transmits the consequences of FINAL-C thoughout the paradigm. ${ }^{4}$

3. DEP constraints are the opposite of MAX constraints. Whereas MAX constraints prohibit deletion, DEP constraints prohibit epenthesis. OO-DEP does more: it prohibits any vowel in a derived form that is not also present in the simple form.

4. Since Cairene Arabic has vowel epenthesis, OO-DEP-V must be crucially dominated. Epenthesis relieves clusters that are phonotactically impossible, as in /katab-t-l-uh/ $\rightarrow$ katabtilu(h) "I wrote to him" or/katab-t-l-ha/ $\rightarrow$ katabtilha "I wrote to her". This shows that OO-DEP-V is ranked below the undominated constraints on syllable structure that compel epenthesis. 
In summary, it has proven possible to construct a typologically responsible analysis of the system of input $\rightarrow$ output mappings described in (3b) and schematized in (6). The relevant constraints and their rankings are given in (16).

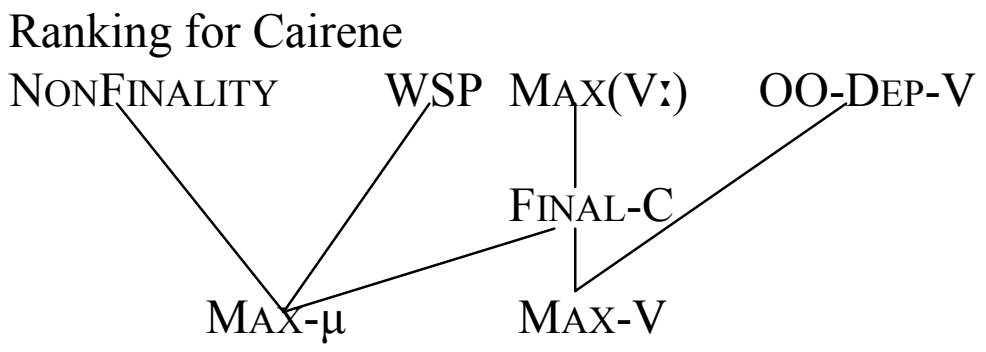

The constraints on the left account for the shortening of word-final long vowels: long vowels shorten finally because the alternative is a final stressed syllable or an unstressed heavy syllable that can be relieved by vowel shortening. On the right, FINAL-C and OO-DEP-V work together to ensure that stem-final short vowels never make it to the surface. When stem-final short vowels are also word-final, they apocopate, and even when they are not word-final, they delete in order to maintain resemblance with the apocopated forms. Since apocope deletes a vowel and its mora together, FINAL-C must dominate both MAX-V and MAX- $\mu$. $\operatorname{MAX}(\mathrm{V}:)$ is ranked above FINAL-C, thereby preventing apocope of long vowels. The result is a chain-shift mapping: $/ \mathrm{V}: / \rightarrow V$ and $/ \mathrm{V} / \rightarrow \varnothing$. This is, of course, the same chain shift that occurred in the history of colloquial Arabic, though it is important to note that diachronic considerations played no role in justifying the analysis presented here.

Tableaux (17)-(20) show how these constraints interact to produce the mappings in (3b) (excluding consonant-final /batak/, which is unremarkable).

(17) $/$ takaba/ $\rightarrow$ takab

\begin{tabular}{|c|c|c|c|c|c|c|c|}
\hline /takaba/ & NONFIN & WSP & $\operatorname{MAX}(V:)$ & OO-DEP-V & FIN-C & MAX- $\mu$ & MAX-V \\
\hline a. takab & & & & & & $*$ & * \\
\hline takaba & & & & & *! & & \\
\hline
\end{tabular}


(18)

/takaba-Sfx/ $\rightarrow$ takab-Sfx

\begin{tabular}{|l||c:c:c:c|c|c|c|}
\hline \multicolumn{1}{|c|}{ takaba-Sfx/ } & NONFIN & WSP & MAX(V: $)$ & OO-DEP-V & FIN-C & MAX- $\mu$ & MAX-V \\
\hline \hline a. $\quad$ takab-Sfx & & & & & & $*$ & $*$ \\
\hline b. takaba-Sfx & & & & $*$ & & & \\
\hline
\end{tabular}

(19) $/$ kabata:/ $\rightarrow$ kabata

\begin{tabular}{|c|c|c|c|c|c|c|c|}
\hline / kabata:/ & NONFIN & WSP & $\operatorname{MAX}(\mathrm{V}:)$ & OO-DEP-V & FIN-C & MAX- $\mu$ & MAX-V \\
\hline a. (kába)ta & & & & & * & * & \\
\hline b. $\quad$ kaba(tá:) & $* !$ & & & & * & & \\
\hline c. (kába)ta: & & $* !$ & & & $*$ & & \\
\hline (kábat) & & & $* !$ & & & $* *$ & $*$ \\
\hline
\end{tabular}

(20)

\begin{tabular}{|c|c|c|c|c|c|c|c|}
\hline / kaba(tá:)-Sfx/ & NONFIN & WSP & $\operatorname{MAX}(V:)$ & OO-DEP-V & FIN-C & MAX- $\mu$ & MAX-V \\
\hline kaba(tá:)-Sfx & & & & & & & \\
\hline
\end{tabular}

In (17), FINAL-C causes apocope of the final short vowel. In (18), the effect of apocope is carried over to the suffixed forms by the agency of OO-DEP-V, which requires that the suffixed stem not contain vowels that are absent from the unsuffixed stem. In (19), a wider range of candidates must be considered. The rejected options include final stress (19b) and an unstressed long vowel (19c). Deletion of a long vowel (19d), though it leads to better satisfaction of FINAL-C, is rejected because of MAX(V:)'s dominance. Finally, in (20) the winner violates none of the constraints under discussion, so it has no serious competitors.

This analysis of stem-final vowels applies with equal force to the vowels of the pronominal suffixes and other clitic-like elements. For example, /ma Sallimu:-ni:- $\int /$ "they didn't teach me" has an underlying stem-final long vowel /u:/ and a suffix-final long vowel /i:/. The surface form is ma Sallimuni if - underlying long vowels are not syncopated, but they are shortened when they do not bear main stress. Without the negation, this word is Sallimúni - the stressless final long vowel is 
shortened, as expected. Suffixes ending in underlying short vowels, though a logical possibility under ROTB, would lose those vowels throughout the paradigm and would therefore be indistinguishable from suffixes ending in consonants. This is just like the short-vowel-final stems in $(17,18)$.

To sum up, ROTB and the universality of CON lead to the conclusion that the alternating stem-final vowel of Cairene Arabic Pabu Pabu:k is underlyingly long. Although this result emerges from theoretical considerations, it also turns out to have solid empirical support in the language. Three additional arguments can be developed.

First, Cairene has phrasal syncope of unstressed high vowels in a two-sided open syllable context, as in (21).

Cairene syncope (Broselow 1976: 3) /mudarris/ huwwa m_darris "he is a teacher" / $\mathrm{irib} /$ ana S_ribt il?ahwa "I drank the coffee" fir_b illahwa "he drank the coffee"

Word-final vowels never delete, however, even when all other requirements are met, as shown in (22).

(22) No word-final syncope (Broselow 1976: 112)

$\begin{array}{lll}\text { /katab-u:/ } & \text { katabu gawa:b "they wrote a letter" } \\ & \text { *katab gawa:b } \\ \text { /ti-ktib-i:/ } & \text { tiktibi gawa:b "you (f. s.) write a letter" } \\ & \text { *tiktib gawarb }\end{array}$

If stem-final vowels are underlying long, then their failure to syncopate even though short is entirely expected under the analysis proposed here. (Broselow (1976: 110) notes this point, but finds that implementing it leads to an ordering paradox in her rule-based account. In parallel OT, ordering paradoxes are of course not a problem.) Undominated MAX(V:) blocks deletion of all underlying long vowels, not only stem-finally but also medially. Because vowels are shortened when they do not bear main stress, there are medial short vowels derived from underlying long 
vowels that do not syncopate either: /ji-firl-u:-na:/ $\rightarrow$ jifilu'na "they ask us". This is another example of $\operatorname{MAX}(\mathrm{V}:)$ 's protective effect.

If stem-final vowels are underlying short, however, special measures must be taken to prevent them from deleting in examples like (22). Broselow (1976: 20) formulates the context of phrasal syncope so as to exclude word-final vowels while allowing deletion in initial and final syllables: $/ \mathrm{V}(\#) \mathrm{C} \_\mathrm{C}(\#) \mathrm{V}$. This rule-specific stipulation, though certainly possible at the time (but see Pyle 1972), does not seem like the right move. One problem is that word-final vowels are also preserved in Arabic dialects with syncope rules that are otherwise very different from Cairene's, an improbable coincidence if non-deletion is stipulated in the rule itself. Furthermore, subsequent developments in prosodic domains theory (e.g., Nespor and Vogel 1986, Selkirk 1978) have made it impossible to reproduce this effect of judicious placement of ' (\#)'.

A second empirical argument in support of underlying long stemfinal vowels comes from the behavior of epenthetic vowels. Imagine if we were to assume underlying short stem-final vowels and adopt, contrary to the typological evidence, a markedness constraint favoring long vowels presuffixally, such as the one in (23).

\section{V:-SFX (straw man)}

$* \breve{v} /$ _Suffix

Appropriately ranked, this constraint would be responsible for unfaithful mappings like /nisi-na/ $\rightarrow$ nisi.na.

Quite apart from the absence of typological support for it, there is a Cairene-internal objection to the constraint V:-SFX. Although stemfinal vowels are long presuffixally, epenthetic vowels are short. In fact, there are minimal pairs like /katabti-luz/ $\rightarrow$ katabti.lu "you (f. sg.) wrote to him" versus /katabt-lu:/ $\rightarrow$ katabtilu "I wrote to him". Under the analysis proposed here, this is expected, since there is no lengthening process and therefore no reason to render an epenthetic vowel as long. But the proponent of presuffixal lengthening must explain why V:-SFX does not affect epenthetic vowels, wrongly yielding *katabti:lu for "I wrote to him". Although the katabtílu/katabtilu minimal pair might encourage the belief that avoidance of homophony somehow blocks 
lengthening in katabtílu (cf. Alderete 1998, 2001, Broselow 1976: 112, Crosswhite 1997, Kenstowicz 2002), epenthetic vowels also fail to lengthen in nouns and prepositions where no ambiguity is possible: /Sand-na:/ $\rightarrow$ Sandina, * Sandi'na "with us (we possess)".

A third point in support of an analysis with underlying stem-final long vowels is the existence in Cairene of a derived contrast between tense and lax short high vowels (Mitchell 1956: 10-11, 112). Long $i$ rand $u_{i}$ are pronounced as the tense vowels [ir] and [u:], while their short

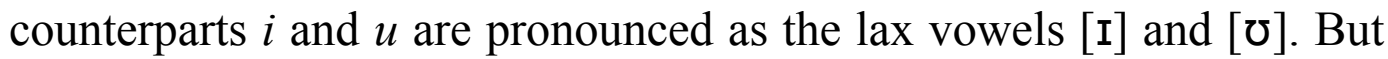
when a surface short vowel is derived from an underlying long vowel, it is pronounced as tense. For instance, fili 'h "take (fem.) it (masc.) away!" is pronounced as [jilísh] and not *[Jlísh]. That is because the vowel of the first syllable is underlying long and has been shortened in an unstressed syllable, as shown by forms like $f i l$ "take away (masc.)". The same goes for [síbha] "leave it (fem.)!", where /ir/ has been shortened in a closed syllable.

According to Mitchell, final short $i$ and $u$ are also pronounced as tense: [jíli] and not *[jílli] for "take away (fem.)". Though the possibility of a final tensing process cannot be entirely discounted (because, e.g., English has one), this observation suggests that final vowels are tense because they are underlyingly long. A weakness of this argument is that it involves a kind of opacity, since tenseness is assigned to vowels that are underlying long, even if they are short at the surface. It therefore brings in the whole issue of the proper treatment of opacity in OT, an issue that goes well beyond the scope of this paper (see McCarthy 2002: 163-6, 184-5 for relevant discussion and references).

\section{Discussion}

By forcing consideration of diverse inputs, ROTB requires greater attention to the mappings that a grammar can perform (see also Lubowicz 2003 on the importance of this point). In Cairene, underlying stems ending in consonants, short vowels, and long vowels are all within the responsibility of the grammar, and so each must map to something that is permissible in the language. Because only two surface patterns actually occur — stem-final consonants and stem-final vowels that alternate between short and long - mappings with neutralization are the 
ones to look at. The viable options were summarized in (3), and each was judged according to a basic criterion of OT: can this mapping system be described by a grammar based on a typologically responsible theory of CON? Only one option survived this test, (3b), and the grammar for it is given in (16).

According to this grammar, an Arabic word like nisi/nisi.na "he forgot/he forgot us" is derived from a stem with an underlying long vowel, /nisi:/. When it occurs word-finally, this long vowel shortens for prosodic reasons (9), and otherwise it is preserved intact. Hypothetical underlying stems that end in short vowels, like/takaba/, lose their final vowels throughout the paradigm, neutralizing with the consonant-final stems: takab, takabna. Language learners, who seek to infer underlying representations from observed output forms, will never be moved to set up actual lexical items that differ in the presence vs. absence of a final short vowel, since this potential underlying distinction is neutralized by the grammar. (This is a case of 'paradigm occultation' (McCarthy 1998), generalizing Prince and Smolensky's (1993) notion of 'Stampean occultation' (cf. Stampe 1973a: 32-33, 1973b: 50-51). See also Tesar and Smolensky (2000:77ff.).) Presumably, in accordance with the principle of Lexicon Optimization (Prince and Smolensky 1993), learners make the obvious move of setting up consonant-final underlying forms when they encounter surface consonant-final stems.

As we saw in section 1, standard phonological accounts of colloquial Arabic have engendered considerable controversy over the correct underlying form for alternating words like nisi/nisi.na. Within OT, there are no grounds for controversy: the underlying form must be /nisiz/. There are two reasons for this difference in results. First, the standard accounts proceed from a limited base that contains only /nisi/ or only /nisiz/, but not both. This means that the grammar is not required to deal with both kinds of inputs, and so its adequacy over both kinds of inputs is never checked. Second, standard accounts do not require typological verifiability, so they are free to include, say, a typologically unsupportable rule of presuffixal lengthening.

Two general properties of OT, ROTB and the universality of CON, have led to a specific conclusion about the phonology of Cairene Arabic: any surface word-final vowel is long in underlying representation, though short at the surface. There is no presuffixal lengthening process, 
contrary to the majority opinion of previous analysts. There is final shortening, however, a process that in Arabic, as in many other languages, is linked with resistance to final stress.

\section{Conclusion}

This paper has argued that richness of the base, when combined with OT's inherent commitment to typology, leads to an improved understanding of problems of indeterminacy in underlying representations. The controversy over the length of Arabic final vowels, a controversy to which many analysts have contributed without a final resolution, disappears once the phenomena are examined from the perspective of ROTB and a typologically responsible CON. It has been suggested (M. Hale and Reiss 1998: 660) that "the notion of richness of the base [is] a computational curiosity of OT grammars that may be quite irrelevant to human language". This analysis of Arabic shows, on the contrary, that ROTB is fundamental to the theory and inextricably linked with the results that OT can achieve.

\section{REFERENCES}

Abdel-Massih, Ernest T., Abdel-Malek, Zaki N., and Badawi, El-Said M. 1979. A Comprehensive Study of Egyptian Arabic, Volume Three (A Preliminary Edition): A Reference Grammar of Egyptian Arabic. Ann Arbor, MI: Center for Near Eastern and North African Studies, University of Michigan.

Abdo, Daud A. 1969. On Stress and Arabic Phonology, A Generative Approach. Beirut: Khayats.

Abdul-Karim, Kamal. 1980. Aspects of the Phonology of Lebanese Arabic. University of Illinois Ph.D. dissertation, Urbana, IL.

Abu-Mansour, Mahasen Hasan. 1987. A Nonlinear Analysis of Arabic Syllabic Phonology, With Special Reference to Makkan. University of Florida Ph.D. dissertation, Gainesville, FL.

Abu-Salim, I. M. 1982. A Reanalysis of Some Aspects of Arabic Phonology: A Metrical Approach. University of Illinois Ph.D. dissertation, Urbana, IL.

Alderete, John. 1998. Morphologically-Governed Accent in Optimality Theory. University of Massachusetts, Amherst Ph.D. dissertation, Amherst, MA.

Alderete, John. 2001. "Dominance effects as transderivational anti-faithfulness". Phonology 18. 201-253.

Angoujard, Jean-Pierre. 1978. "Le cycle en phonologie? L'accentuation en Arabe Tunisien". Analyses, Théorie 3. 1-39. 
Aronoff, Mark, Arsyad, Azhar, Basri, Hassan, and Broselow, Ellen. 1987. "Tier configuration in Makassarese reduplication". CLS 23: Parasession on Autosegmental and Metrical Phonology ed. by A. Bosch, E. Schiller, and B. Need, 1-15. Chicago: Chicago Linguistic Society

Beckman, Jill. 1998. Positional Faithfulness. University of Massachusetts, Amherst Ph.D. dissertation, Amherst, MA. [Available on Rutgers Optimality Archive, ROA-234. Excerpted in Optimality Theory in Phonology: A Reader, ed. by John J. McCarthy, Malden, MA and Oxford, Blackwell (2004).]

Benua, Laura. 1997. Transderivational Identity: Phonological Relations between Words. University of Massachusetts, Amherst Ph.D. dissertation, Amherst, MA. [Available on Rutgers Optimality Archive, ROA-259. Published (2000) as Phonological Relations Between Words, New York: Garland. Excerpted in Optimality Theory in Phonology: A Reader, ed. by John J. McCarthy, Malden, MA and Oxford, Blackwell (2004).]

Bohas, Georges. 1978. "Quelques processus phonologiques dans l'Arabe de Damas". Analyses, Théorie 1. 87-152.

Brame, Michael. 1971. "Stress in Arabic and generative phonology [Review article]". Foundations of Language 7. 556-591.

Broselow, Ellen. 1976. The Phonology of Egyptian Arabic. University of Massachusetts, Amherst Ph.D. dissertation, Amherst, MA.

Chomsky, Noam, Halle, Morris, and Lukoff, Fred. 1956. "On accent and juncture in English". For Roman Jakobson: Essays on the Occasion of His Sixtieth Birthday, 11 October, 1956 ed. by Morris Halle, Horace Lunt, and H. Maclean, 65-80. The Hague: Mouton

Crosswhite, Katherine. 1997. Intra-paradigmatic homophony avoidance in two dialects of Slavic. Unpublished manuscript. Los Angeles.

de Lacy, Paul. 1998. Sympathetic stress. Unpublished manuscript. Amherst, MA. [Available on Rutgers Optimality Archive.]

Glover, Bonnie Carol. 1988. The Morphophonology of Muscat Arabic. UCLA Ph.D. dissertation, Los Angeles.

Gouskova, Maria. 2003. Deriving Economy: Syncope in Optimality Theory. University of Massachusetts, Amherst Ph.D. dissertation, Amherst, MA. [Available on Rutgers Optimality Archive, ROA-610.]

Haddad, Ghassan. 1984. Problems and Issues in the Phonology of Lebanese Arabic. University of Illinois Ph.D. dissertation, Urbana, IL.

Hale, Kenneth. 1973. "Deep-surface canonical disparities in relation to analysis and change: An Australian example". Current Trends in Linguistics ed. by Thomas Sebeok, 401-458. The Hague: Mouton

Hale, Mark and Reiss, Charles. 1998. "Formal and empirical arguments concerning phonological acquisition". Linguistic Inquiry 29. 656-683. [Available on Rutgers Optimality Archive.]

Halle, Morris and Zeps, Valdis. 1966. "A survey of Latvian morphophonemics". Quarterly Progress Report of the Research Laboratory of Electronics 83. 104-113. 
Hamid, Abdel Halim M. 1984. A Descriptive Analysis of Sudanese Colloquial Arabic Phonology. University of Illinois Ph.D. dissertation, Urbana, IL.

Harms, Robert T. 1981. "A backwards metrical approach to Cairo Arabic stress". Linguistic Analysis 7. 429-450.

Harris, Zellig. 1942. "Morpheme alternants in linguistic analysis". Language 18. 169-180.

Hayes, Bruce. 1995. Metrical Stress Theory: Principles and Case Studies. Chicago: The University of Chicago Press.

Howard, Irwin. 1972. A Directional Theory of Rule Application in Phonology. MIT Ph.D. dissertation, Cambridge, MA.

Ito, Junko and Mester, Armin. 1995. "Japanese phonology". Handbook of Phonological Theory ed. by John Goldsmith, 817-838. Cambridge, MA: Blackwell

Jensen, J. T. 1977. Yapese Reference Grammar. Honolulu: University Press of Hawaii.

Kager, René. 1999. Optimality Theory. Cambridge: Cambridge University Press.

Kaneko, Ikuyo and Kawahara, Shigeto. 2002. "Positional faithfulness theory and the emergence of the unmarked: The case of Kagoshima Japanese". ICU English Studies 5. 18-36.

Kenstowicz, Michael. 2002. "Paradigmatic uniformity and contrast". MIT Working Papers in Linguistics 42. [Available (23 May 2003) at http://web.mit.edu/linguistics/www/kenstowicz/paradigm_contrast.doc.]

Kenstowicz, Michael and Abdul-Karim, Kamal. 1980. "Cyclic stress in Levantine Arabic". Studies in the Linguistic Sciences 10(2). 55-76.

Kiparsky, Paul. 1982. "Lexical phonology and morphology". Linguistics in the Morning Calm ed. by I. S. Yang, 3-91. Seoul: Hanshin

Kiparsky, Paul. 2003. "Syllables and moras in Arabic". The Syllable in Optimality Theory ed. by Caroline Féry and Ruben van de Vijver, 147-182. Cambridge: Cambridge University Press

Kirchner, Robert. 1996. "Synchronic chain shifts in Optimality Theory". Linguistic Inquiry 27. 341-350. [Available on Rutgers Optimality Archive, ROA-66.]

Lightner, Theodore. 1972. Problems in the Theory of Phonology. Edmonton: Linguistic Research, Inc.

Lubowicz, Anna. 2003. Contrast Preservation in Phonological Mappings. University of Massachusetts, Amherst Ph.D. dissertation, Amherst, MA. [Available on Rutgers Optimality Archive, ROA-554.]

McCarthy, John J. 1979. "On stress and syllabification". Linguistic Inquiry 10. 443466.

McCarthy, John J. 1993. "A case of surface constraint violation". Canadian Journal of Linguistics 38. 169-195.

McCarthy, John J. 1998. "Morpheme structure constraints and paradigm occultation". CLS 32, Part 2: The Panels ed. by M. Catherine Gruber, Derrick Higgins, Kenneth Olson, and Tamra Wysocki, 123-150. Chicago, IL: Chicago Linguistic Society 
McCarthy, John J. 2002. A Thematic Guide to Optimality Theory. Cambridge: Cambridge University Press.

McCarthy, John J. and Prince, Alan. 1990. "Prosodic morphology and templatic morphology". Perspectives on Arabic linguistics II: Papers from the Second Annual Symposium on Arabic Linguistics ed. by Mushira Eid and John J. McCarthy, 1-54. Amsterdam: John Benjamins

McCarthy, John J. and Prince, Alan. 1993. Prosodic Morphology: Constraint Interaction and Satisfaction. New Brunswick, NJ: Rutgers University Center for Cognitive Science. [Available on Rutgers Optimality Archive, ROA482.]

McCarthy, John J. and Prince, Alan. 1994. "The emergence of the unmarked: Optimality in prosodic morphology". Proceedings of the North East Linguistic Society 24 ed. by Mercè Gonzàlez, 333-379. Amherst, MA: GLSA Publications.[Available on the Rutgers Optimality Archive, ROA-13. Excerpted in Optimality Theory in Phonology: A Reader, ed. by John J. McCarthy, Malden, MA and Oxford, Blackwell (2004).]

McCarthy, John J. and Prince, Alan. 1995. "Faithfulness and Reduplicative Identity". University of Massachusetts Occasional Papers in Linguistics 18 ed. by Jill Beckman, Laura Walsh Dickey, and Suzanne Urbanczyk, 249-384. Amherst, MA: GLSA Publications.[Available on Rutgers Optimality Archive, ROA103.]

McCarthy, John J. and Prince, Alan. 1999. "Faithfulness and identity in Prosodic Morphology". The Prosody-Morphology Interface ed. by René Kager, Harry van der Hulst, and Wim Zonneveld, 218-309. Cambridge: Cambridge University Press.[Excerpted in Optimality Theory in Phonology: A Reader, ed. by John J. McCarthy, Malden, MA and Oxford, Blackwell (2004).]

Mitchell, T. F. 1956. An Introduction to Egyptian Colloquial Arabic. Oxford: Oxford University Press.

Mohanan, K. P. 1986. The Theory of Lexical Phonology. Dordrecht: Reidel.

Moreton, Elliott. 2003. "Non-computable functions in Optimality Theory". Optimality Theory in Phonology: A Reader ed. by John J. McCarthy, 141163. Malden, Mass., and Oxford, UK: Blackwell.[Available on Rutgers Optimality Archive, ROA-364.]

Moreton, Elliott and Smolensky, Paul. 2002. "Typological consequences of local constraint conjunction". Proceedings of the 21st West Coast Conference on Formal Linguistics ed. by Line Mikkelsen and Christopher Potts, 306-319. Cambridge, MA: Cascadilla Press.[Available on Rutgers Optimality Archive, ROA-525.]

Nespor, Marina and Vogel, Irene. 1986. Prosodic Phonology. Dordrecht: Foris.

Payne, David L. 1981. The Phonology and Morphology of Axininca Campa: The Summer Institute of Linguistics and University of Texas at Arlington.

Piggott, G. L. 1975. "More on the application of phonological rules". Montreal Working Papers in Lingustics 5. 113-150. 
Piggott, G. L. 1991. "Apocope and the licensing of empty-headed syllables". The Linguistic Review 8. 287-318.

Prince, Alan. 1990. "Quantitative consequences of rhythmic organization". Parasession on the Syllable in Phonetics and Phonology ed. by M. Ziolkowski, M. Noske, and K. Deaton, 355-398. Chicago: Chicago Linguistic Society

Prince, Alan (1996) Aspects of mapping under OT. Handout from Colloquium, University of California, Santa Cruz.

Prince, Alan and Smolensky, Paul. 1993. Optimality Theory: Constraint interaction in generative grammar. New Brunswick, NJ: Rutgers University Center for Cognitive Science. [Excerpts appear in Optimality Theory in Phonology: A Reader, ed. by John J. McCarthy, Malden, MA and Oxford, Blackwell (2004). Available on Rutgers Optimality Archive, ROA-537.]

Pyle, Charles. 1972. "On eliminating BMs". Proceedings of CLS 8 ed., 516-532

Raffelsiefen, Renate. 1999. "Constraints on schwa apocope in Middle High German". Analogy, Leveling, Markedness ed. by Aditi Lahiri. Berlin and New York: Mouton de Gruyter

Selkirk, Elisabeth. 1978. "On prosodic structure and its relation to syntactic structure". Nordic Prosody ed. by T. Fretheim, 111-140. Trondheim: TAPIR

Siptár, Péter and Törkenczy, Miklós. 2000. The Phonology of Hungarian. Oxford: Oxford University Press.

Sohn, Ho-min. 1975. Woleaian Reference Grammar. Honolulu: University of Hawaii Press.

Spring, Cari. 1990. Implications of Axininca Campa for Prosodic Morphology and Reduplication. University of Arizona Ph.D. dissertation, Tucson, AZ.

Stampe, David. 1973a. A Dissertation on Natural Phonology. University of Chicago Ph.D. dissertation, Chicago. [Published by Garland, New York, 1979.]

Stampe, David. 1973b. "On chapter nine". Issues in Phonological Theory ed. by Michael J. Kenstowicz and Charles W. Kisseberth, 44-52. The Hague: Mouton

Tesar, Bruce, Grimshaw, Jane, and Prince, Alan. 1999. "Linguistic and cognitive explanation in Optimality Theory". What is Cognitive Science? ed. by Ernest Lepore and Zenon Pylyshyn, 295-326. Oxford: Blackwell

Tesar, Bruce and Smolensky, Paul. 2000. Learnability in Optimality Theory. Cambridge, MA: MIT Press.

Watson, Janet C. E. 2002. The Phonology and Morphology of Arabic. Oxford: Oxford University Press.

Welden, Elizabeth Ann. 1977. Prosodic Aspects of Cairo Arabic Phonology. University of Texas, Austin Ph.D. dissertation, Austin,TX.

Welden, Elizabeth Ann. 1980. "Stress in Cairo Arabic". Studies in the Linguistic Sciences 10(2). 99-120.

Wilbur, Ronnie. 1974. The Phonology of Reduplication. University of Illinois Ph.D. dissertation. 